\title{
FOREIGN DIRECT INVESTMENTS AND ECONOMIC GROWTH: HOW WELL DOES THE TECHNOLOGY CHANNEL WORK IN TURKEY?*
}

\author{
Yusuf BAYRAKTUTAN** \\ Meltem Tarı ÖZGÜR***
}

\begin{abstract}
The main purpose of this study is to assess the impact of the technology spillovers as a driving force for economic growth of Turkey in terms of manufacturing industry using the data of 1988-2012 period. For this aim, the dynamic interactions between export of the manufacturing industry (EXP) as a measure of technology spillover, gross domestic product (GDP), gross fixed capital formation (GFCF) and FDI in manufacturing industry were investigated via cointegration and causality tests in addition to the innovation accounting techniques in the vector autoregressive (VAR) framework. While the cointegration test yields no clear evidence of long-run equilibrium relationship among these variables Granger causality test indicates that there is a univariate causality running from the EXP to the all other variables, and FDI is not Granger cause for the other variables. Nevertheless, the positive impact of FDI on the GDP and EXP variables is observed within the results of the innovation accounting analysis. From this point of view, it is concluded that the FDI leads economic growth more significantly in indirect ways rather than through direct ways. Under the light of these empirical outcomes, proposing policies based on strategies which encourage FDI inflows to the sub-sectors of manufacturing industry with higher technological gaps seem as effective and valuable in terms of promoting economic growth.
\end{abstract}

Keywords: Foreign direct investment, economic growth, manufacturing industry, technology spillovers.

Jel Codes: F21, O30, O40

\section{INTRODUCTION}

Stable and sustainable growth is among primary objectives, as well as the base of welfare increase. In this context, it is necessary to benefit from foreign direct investments (FDI) alongside

\footnotetext{
* This paper was derived from the second author's PhD Thesis under the first author's supervision.

** Prof. Dr., Kocaeli University, Department of Economics, ybayraktutan@kocaeli.edu.tr

*** PhD., meltemtari@gmail.com

Date of submission: 02.12 .2016

Date of acceptance: 12.04 .2017
} 
local resources and saving-investment activities to develop productive capacity with appropriate structural transformation. The interaction between foreign direct investments (FDI) and economic growth is one of the frequently discussed issues in the literature, both theoretically and empirically. The role of different channels through which FDI promotes economic growth is an aspect that should be focused on.

In line with technological developments in electronics, communication and transportation, worldwide multinational enterprises (MNEs) have carried out their production activities to different geographical areas. Thus, the share of FDI in the world economy has increased gradually.

Economic literature on FDI, which has been expanded after 1970s, is related especially with the impacts of these investments on economic growth at host countries. Considering this relationship there are a lot of positive and negative impacts that can be dealt with. In the context of these impacts, making a contribution to income and employment growth through technology and knowledge spillovers are the positive ones and causing environmental degradation and crowding out domestic investments and domestic financial resources are the negative ones.

In this study, the positive impacts of FDI on economic growth through both gross fixed capital formation, and exportation realized thanks to technology and knowledge externalities and spillovers and the development of competitiveness will be discussed, and the impact of FDI on economic growth in Turkey has been researched with a special attention to technology channel. From this point of view, the manufacturing industry, which owns the most of the technology spillovers stem from FDI, has been investigated. The contribution of inward FDI in the manufacturing industry to economic growth has been inquired by taking the exports of the manufactured products (EXP) and gross fixed capital formation (GFCF) into consideration.

\section{FDI AND TURKISH EXPERIENCE}

FDI is a kind of international investment that made by an investor in one country with a resident FDI establishment in another country, for the purpose of establishing a longlasting relationship based on interest and getting permanent income. The concept of "permanent income” points out long-term relationship between investor and enterprise, and the efficiency of foreign direct investor in control of the enterprise. Permanent income realized depends upon $10 \%$ or more control use of investor. It does not involve only the first transaction which lead to connection between investor and enterprise, but also their all former transactions with subsidiary enterprises (Duce, 2003: 2; Durlauf, and Blume, 2008; IMF, 2009: 101; OECD, 2009: 17). 
FDI have a lot of contributions to host countries. Especially, in developing countries, they lead to new employment areas, increase foreign exchange reserves of host countries, obtain capital accumulation that is the most important factor for national income increasing, transfer higher technology. Through acquisition of new technologies, new knowledge and skills in host countries, will be important outcomes. The most important channel for developing countries would be technology spillover as a result of FDI inflows. (Sonmez and Pamukcu, 2011: 3).

It is assumed that technology level of home country is superior than host countries'. Although the utilization capacity of countries and firms from the technology of foreign ones can be differed, it is possible to produce much more and cheaper, and more qualified goods and services, and to provide increases in consumer welfare in all host countries (Lipsey and Sjöholm, 2005: 24).

FDI benefit to developing countries by improving technology level as a result of both efficient use of technology and the adoption of this technology by local firms. Inward FDI, which include capital flows as well as technology transfer, play an increasing role in economic growth for the host country by either channels (Saggi, 2002: 208, 217).

The developments of electronics, machinery, transportation, knowledge and communication technologies have been decreased investment costs which countries are faced with and have had an important role for the investment decisions in micro and macro frame in particular by 2000s. As well as these improvements, increased trade openness has positively affected technology spillovers.

As of 1980s, Turkey has liberalized the real and financial sectors, increased the openness ratio despite instable macroeconomic environment, and parallel to this, the volume of FDI has expanded. This process has been accelerated particularly at the 2000s with the exception of the economic crisis of 2001 when FDI inflows decreased. After this crisis Turkey made some important legal regulations to attract FDI which are more credible than speculative short-term investments.

Law 4875 on FDI which goes in effect in 2003 instead of Law 6224 on Encouragement of Foreign Capital brought important changes. FDI has been encouraged, foreign investors have been considered equal to domestic ones, and their rights have been protected, and permission and approval system has been transformed into information system. With the legislative regulations mentioned above, and the acceleration of the negotiations for the EU membership, Turkey has experienced a clear increase in FDI inflows particularly in the period of 2003-2012. 


\section{LITERATURE REVIEW}

In spite of the existence of attempts to determine the efficiency of different channels on which FDI support economic growth, using microeconomic and macroeconomic variables, empirical studies about these channels are quite limited.

Borenzstein, et. al. (1998) tested the effect of FDI on economic growth in a cross-country regression framework utilizing data on FDI flows from industrial countries to 69 developing countries over two decades, and suggested that FDI are an important vehicle for the transfer of technology, contributing relatively more to growth than the domestic investments.

Hansen, and Rand (2005) investigated FDI-GDP relationship for 31 developing countries for the period of 1970-2000. They observed a strong long-term causality relationship between FDI and GDP. Additionally, the higher FDI in gross capital formation, the higher positive impact on GDP.

Kar, and Tatlisoz (2008) investigated Turkey’s inward FDI determinants for 1980-2003 period. They found a positive relationship between inward FDI and net international reserves, gross national product (GNP), openness ratio, electrical power production index, and investment incentives; and a negative relationship between inward FDI and real exchange rate, and labor costs.

Wang (2009) using a panel data analysis for 12 Asian economies over the period of 19871997 put forward that total FDI flows considerably affect economic growth through manufacturing sectors which have a significant role and positive effect on this variable.

Chimobi (2010) examined the contribution of FDI and exportation on economic growth by using cointegration and Granger causality tests. According to this study, there is a bilateral but statistically insignificant relationship between FDI and economic growth.

Turan Koyuncu (2010) studied inward FDI of Turkey for the period of 1990-2009, using structural vector autoregressive analysis. According to this study, inward FDI are significantly influenced from the amount of FDI of the former period, GDP, trade openness and alternation of the net international reserves.

Doytch, and Uctum (2011) put forward that total FDI increase economic growth usually by the channel of manufacturing sector, especially in Latin America and Caribbean Region, Europe and Central Asia, low-income countries and economies with large manufacturing basis. 
Sonmez, and Pamukcu (2011) using the data of 2003-2006 period, investigated the existence of intra-industry technology spillovers which related with FDI in Turkish manufacturing industry. For the related period, the presence of the horizontal technology spillovers which tend towards the local firms from the foreign ones that operate in the same industry and which have a positive effect on the growth of the firms through increasing total factor productivity is available. On the other hand, for the firms which operate locally, such a relationship is not observed. For these firms, FDI related spillovers have a very little impact on total factor productivity and growth rates, and there is a poor connection between the manufacture exporters and the foreign firms operating in Turkey.

Our analysis differs from the current literature in terms of model and variables selected, sample, time period and methodology, and address an important aspect of FDI, specifically technological reflection at the context of economic growth which is main drive of international competitiveness and export performance.

\section{DATA AND METHODOLOGY}

Variables were chosen assuming that changes in GDP reflects economic growth and exports of manufacturing industry is an indicator of structural change of the economy. The data on the variables GDP, GFCF, FDI and EXP that are used in the empirical analysis covers the period of 1988 to 2012, and were obtained from the Central Bank of the Republic of Turkey, various issues of the FDI bulletins published by the Ministry of Economy, and the World Development Indicators by the World Bank. The data were constructed in the annual basis, due to the lack of the monthly/quarterly series, and expressed in logs to address the skewness. The length of the data can be assumed to be moderate and adequate to reach enough degrees of freedom for estimation of long and short-run relationships among the variables. A well-known econometrics package for time series analysis was used. The summary of descriptive statistics of data is in Table-1.

A four-step procedure was employed as the estimation strategy for the dynamic interaction between the variables. These procedures are the unit root test, the cointegration and the Granger causality tests in the vector autoregression (VAR) framework, and the innovation accounting techniques including both the impulse response function analysis and the forecast error variance decomposition method. 
Table 1: Summary statistics of the data

\begin{tabular}{rcccc}
\hline Statistics & FDI & GDP & GFCF & EXP \\
\hline Mean & $1.13 \mathrm{E}+09$ & $3.49 \mathrm{E}+11$ & $7.25 \mathrm{E}+10$ & $4.22 \mathrm{E}+10$ \\
Median & $5.04 \mathrm{E}+08$ & $2.50 \mathrm{E}+11$ & $5.02 \mathrm{E}+10$ & $2.26 \mathrm{E}+10$ \\
Maximum & $4.29 \mathrm{E}+09$ & $7.89 \mathrm{E}+11$ & $1.69 \mathrm{E}+11$ & $1.19 \mathrm{E}+11$ \\
Minimum & $2.07 \mathrm{E}+08$ & $9.09 \mathrm{E}+10$ & $2.37 \mathrm{E}+10$ & $7.49 \mathrm{E}+09$ \\
Std. Dev. & $1.31 \mathrm{E}+09$ & $2.37 \mathrm{E}+11$ & $4.70 \mathrm{E}+10$ & $3.66 \mathrm{E}+10$ \\
Skewness & 1.6288 & 0.7631 & 0.8430 & 0.8217 \\
Kurtosis & 4.0866 & 2.0264 & 2.2030 & 2.1859 \\
Jarque-Bera & 12.2845 & 3.4137 & 3.6228 & 3.5038 \\
Probability & 0.0022 & 0.1814 & 0.1634 & 0.1734 \\
Sum & $2.82 \mathrm{E}+10$ & $8.72 \mathrm{E}+12$ & $1.81 \mathrm{E}+12$ & $1.05 \mathrm{E}+12$ \\
Sum Sq. Dev. & $4.15 \mathrm{E}+19$ & $1.34 \mathrm{E}+24$ & $5.31 \mathrm{E}+22$ & $3.21 \mathrm{E}+22$ \\
Observations & 25 & 25 & 25 & 25 \\
\hline
\end{tabular}

\section{IV.I. Unit Root Test}

Most of the macroeconomic variables increase over the time period and they frequently indicate nonstationary time series. Different definitions of stationarity exist in the recent literature. However, mean stationarity is the most widely used concept for many applications due to the strict assumptions of the rest of the definitions. The main assumption of the mean stationarity concept is that the mean of the time series is time invariant.

Nonstationarity in time series yields misleading parameter estimates. In other words, using nonstationary time series leads spurious regression between the variables yielding erroneous conclusions. This is why checking the stationarity of the time series before modeling is a mandatory procedure. The presence of the nonstationarity and the order of the integration for each of the variables are checked with the Augmented Dickey-Fuller (ADF) unit root test. ADF test uses the estimation of the following equation for each of the time series (Dickey and Fuller, 1981):

$$
\Delta X_{t}=\delta_{0}+\delta_{1} t+\delta_{2} X_{t-1}+\sum_{i=1}^{k} \alpha_{i} \Delta X_{t-i}+\varepsilon_{i}
$$

where, $\Delta$ is the first difference operator, $X_{t}$ denotes the natural logarithm of the variable $X$ at time $t$, $\delta_{0}, \delta_{1}, \delta_{2}$, and $\alpha_{i}$ are parameters to be estimated, $k$ denotes the number of the augmenting lags used and $\varepsilon_{i}$ is the white noise process. 
The number of the augmenting lags used in the ADF test to rid the serial correlation of the residuals which bias the results is selected automatically based on info criteria. The ADF test was conducted with constant and time trend in addition to constant for the levels of the variables and their first differenced form. The null hypothesis of the ADF test states that there is a unit root, and the presence of a unit root implies the nonstationarity of the time series. Calculated $t$-statistics were compared with the critical values at conventional degrees of significance to make a decision on stationarity. If the absolute value of the calculated $t$-statistics is higher than the absolute value of the critical value, then the null hypothesis should be rejected. Stationarity of the time series was also confirmed by the inspection of the autocorrelation and partial autocorrelation functions (also known as correlogram and partial correlogram, respectively).

\section{IV.II. Cointegration Test}

Cointegration test is basically used to capture whether the linear combination (weighted average) of a set of nonstationary time series is stationary or not. If the linear combination of these time series is nonstationary, then a cointegration does not exist among time series. Otherwise, in a case where a cointegration does exist since they are integrated of the same order, it can be interpreted as a valid empirical evidence of a long-run relationship which does not diverge over time. EngleGranger, Phillips-Ouliaris and Johansen-Juselius (henceforth JJ) methods are well-known procedures for testing the cointegration. In this study, $\mathrm{JJ}$ as a multivariate method which gives invariant results with respect to the direction of the normalization by making all the variables explicitly endogenous was preferred due to the number of the variables in the data set.

A VAR of order $p$ that is used for estimating the cointegration matrix is the first step for the $\mathrm{JJ}$ method as given in Eq.2:

$$
y_{t}=\mu+A_{1} y_{t-1}+\ldots+A_{p} y_{t-p}+\varepsilon_{t}
$$

where $\mu$ is any constant, $\varepsilon_{t}$ is the white noise process and $y_{t}$ denotes the variable $y$ at time $t$. It is crucial to determine the appropriate lag length of the VAR model. Because if the chosen lag length is less than the appropriate value, there will be a model misspecification. On the other hand, the lag length is limited for mainly three reasons: lag lengths over the appropriate value may consume additional degree of freedom, lead inefficient estimations and increase the computational time. The lag length can be selected through some criteria such as sequential modified LR test statistics, final prediction error (FPE), Akaike information criterion (AIC), Hannan-Quinn information criterion (HQ) and Schwarz information criterion (SIC). Constructing of the VAR model with an appropriate lag length 
will make the residuals uncorrelated and homoskedastic. The appropriateness of the selected lag length can be confirmed by normality, autocorrelation and stability tests.

After the cointegration matrix is obtained with the estimation of the VAR model with the appropriate lag length, trace and maximum eigen-value of the cointegration matrix should be calculated. These are the two test statistics that are offered in the JJ method to determine the rank(s) ( $r$ ) which shows the number of the cointegration vector(s) by making a decision on the tested hypotheses.

Trace and maximum eigen-value tests rarely lead different conclusions. However, trace test is a joint test whereas the maximum eigen-value test considers all of the eigen-values. Trace and maximum eigen-value statistics can be calculated as follows, respectively.

$$
\begin{aligned}
& \lambda_{\text {trace }}(r)=-T \sum_{i=r+1}^{k} \ln \left(1-\hat{\lambda}_{i}\right) \\
& \lambda_{\text {max }}(r, r+1)=-T \ln \left(1-\hat{\lambda}_{r+1}\right)
\end{aligned}
$$

where $T$ and $\hat{\lambda}_{i}$ are the length of the sample and the value of $i^{\text {th }}$ largest canonical correlation, respectively. If the calculated values of the trace and maximum eigen-value statistics are higher than the critical values for the selected significance level, then the null hypothesis of cointegration vector can be rejected.

\section{IV.III. Granger Causality Test}

If the variables of a data set are integrated of order one and also cointegrated, then a casual linkage must run among the variables in at least one direction. However, the cointegration test does not point out the direction of the linkage. Additionally, the presence of a casual linkage among the variables is independent of the existence of a cointegration vector. Therefore, adequate evidence for full clarification of the casual relationships cannot be obtained by only the cointegration test. In this study, Granger causality test is employed in order to assess the direction of the casual linkages, if exists, between the variables.

Granger causality has been frequently estimated via VAR models in the recent literature. However, specifications of the VAR model depend on the outcomes of the unit root and cointegration tests. When all of the variables in concern are stationary, a VAR model in levels should be used. As another case, a VAR model in the first differences should be used if the related variables are integrated of order one and also not cointegrated. Finally, when the variables are integrated of order one and 
also cointegrated, an estimation of the vector error correction model in the first differences as given in Eq. 5 should be conducted:

$$
\begin{aligned}
\Delta L G D P_{t}= & \alpha_{1}+\sum_{i=1}^{p} \chi_{i} \Delta L G D P_{t-i}+\sum_{i=1}^{p} \beta_{i} \Delta L G F C F_{t-i}+ \\
& \sum_{i=1}^{p} \vartheta_{i} \Delta L E X P_{t-i}+\sum_{i=1}^{p} \theta_{i} \Delta L F D I_{t-i}+\psi_{1} E C T_{t-1}+\varepsilon_{1 t} \\
\Delta L_{G F C F_{t}=} & \alpha_{2}+\sum_{i=1}^{p} \chi_{i} \Delta L G D P_{t-i}+\sum_{i=1}^{p} \beta_{i} \Delta L G F C F_{t-i}+ \\
& \sum_{i=1}^{p} \vartheta_{i} \Delta L E X P_{t-i}+\sum_{i=1}^{p} \theta_{i} \Delta L F D I_{t-i}+\psi_{2} E C T_{t-1}+\varepsilon_{2 t} \\
\Delta L E X P_{t}= & \alpha_{3}+\sum_{i=1}^{p} \chi_{i} \Delta L G D P_{t-i}+\sum_{i=1}^{p} \beta_{i} \Delta L G F C F_{t-i}+ \\
& \sum_{i=1}^{p} \vartheta_{i} \Delta L E X P_{t-i}+\sum_{i=1}^{p} \theta_{i} \Delta L F D I_{t-i}+\psi_{3} E C T_{t-1}+\varepsilon_{3 t} \\
\Delta L F D I_{t}= & \alpha_{4}+\sum_{i=1}^{p} \chi_{i} \Delta L G D P_{t-i}+\sum_{i=1}^{p} \beta_{i} \Delta L G F C F_{t-i}+ \\
& \sum_{i=1}^{p} \vartheta_{i} \Delta L E X P_{t-i}+\sum_{i=1}^{p} \theta_{i} \Delta L F D I_{t-i}+\psi_{4} E C T_{t-1}+\varepsilon_{4 t}
\end{aligned}
$$

where $\Delta, L, p, \varepsilon_{1 t}$ and $E C T_{t-1}$ refer to the first difference operator, natural logarithm, optimal lag length, white noise process and one period lagged error correction term, respectively. The error correction term should be excluded if there is no cointegration among the variables.

\section{IV.IV. Techniques For Innovation Accounting}

Causality tests cannot capture all interactions between the variables of a multivariate VAR model. Interpreting the VAR model via impulse response function and variance decomposition techniques gives a complementary perspective for clarifying the dynamic relationships among the variables in concern. For this aim, the VAR model should be represented in the form of a vector moving average process. The casual ordering of the variables which can be determined with the help of the causality tests or macroeconomic assumptions is an important parameter for obtaining proper results when these two techniques are employed.

Impulse response functions of a VAR model give the opportunity to simulate the instantaneous and continuing response of an endogenous variable over the selected response horizon to a one time and one unit shock (innovation) of that variable and the rest of the endogenous variables in the model. In general, the shock that is introduced to the system is one standard deviation shock in 
the error term of the variable. Typically, the impulse response functions considerably differ with the selected horizon length.

On the other hand, the proportion of the movement in a sequence due to its own shocks versus shocks to the other variables can be determined by the forecast error variance decomposition (Enders, 1995: 311). Forecast error is the difference between the actual value and the value estimated by the model. If the forecast error variance of a variable in a system cannot be explained at any of the forecast periods by the shocks of the rest of the variables, then that variable should be concluded as exogenous. Otherwise, that variable can be assumed as endogenous. Typically, variables can explain their forecast error variance with higher proportions in short horizons and with lower proportions in long horizons. Relative importance of the variables in a particular variable can be achieved by comparing their ability to explain the forecast error variance of that particular variable.

\section{ESTIMATION AND RESULTS}

Results of the unit root, cointegration and causality tests are included in this section. Impulse response functions and forecast error variance decomposition of the estimated VAR model are also presented.

\section{V.I. Stationarity}

Result of the ADF unit root test that was utilized to check for the stationarity of the variables is reported in Table-2. The lag length of ADF test was chosen automatically with a maximum lag length of 5 based on the SIC.

Table 2: Results of the ADF unit root test

\begin{tabular}{ccccc}
\hline & \multicolumn{2}{c}{ Only constant $^{1}$} & \multicolumn{2}{c}{ Constant $^{2}$ trend $^{2}$} \\
\hline Time series & T-Statistic & Probability $^{*}$ & T-Statistic & Probability $^{*}$ \\
\hline LGDP & -0.82 & 0.7928 & -2.53 & 0.3115 \\
DLGDP & -5.48 & 0.0002 & -5.34 & 0.0014 \\
LGFCF & -0.87 & 0.7778 & -2.35 & 0.3910 \\
DLGFCF & -5.42 & 0.0002 & -5.29 & 0.0015 \\
LEXP & -0.01 & 0.9481 & -2.17 & 0.4823 \\
DLEXP & -4.36 & 0.0025 & -4.24 & 0.0142 \\
LFDI & -1.44 & 0.5428 & -2.50 & 0.3229 \\
DLFDI & -5.47 & 0.0002 & -5.44 & 0.0011 \\
\hline
\end{tabular}

${ }^{1}$ Critical values for the ADF test are $-3.737,-2.991$ and -2.635 for the significance levels of $1 \%, 5 \%$ and $10 \%$, respectively.

${ }^{2}$ Critical values for the ADF test are $-4.394,-3.612$ and -3.243 for the significance levels of $1 \%$, $5 \%$ and $10 \%$, respectively.

"MacKinnon (1996) one-sided p-values.

$\mathrm{L}$ denotes that the variable is expressed in logs and $\mathrm{D}$ denotes the first difference. 
Table-2 indicates that the null hypothesis of the unit root cannot be rejected for all of the variables in their levels at 1\%, 5\% and $10 \%$ level of significance in only constant and constant with trend conditions. However, when the first differenced variables are considered, the null hypothesis can be rejected under the same conditions.

Stationarity of the first differenced variables was also checked with autocorrelation and partial autocorrelation functions. When the correlogram and partial correlogram were considered, both correlation values were in the $95 \%$ confidence bounds, confirming that all of the variables are stationary in their first differences. Thus, it is concluded that all of the variables are integrated of order 1 or $I(1)$.

\section{V.II. Long-Run Relationships}

Cointegration test with JJ procedure was carried out for uncovering the long-run relationships among the variables. Selection of the appropriate lag length is a preliminary procedure and Table-3 reports the FPE, AIC, HQ and SIC criteria for lag length selection. In accordance with Table-3, the optimal lag length has been identified as 1 , whereas all of the criteria confirm the selection. Also, the roots of the inverse characteristic polynomial of the VAR model were inside the unit circle of the complex plain, indicating that the modulus of all of the inverse roots is smaller than unity, and the stability of the VAR model with 1 lag length is confirmed.

Table 3: Selection of the appropriate lag length

\begin{tabular}{ccccccc}
\hline Lag & LogL & LR & FPE & AIC & SIC & HQ \\
\hline 0 & -17.990 & NA & $8.69 \mathrm{E}-05$ & 1.999 & 2.198 & 2.046 \\
1 & 49.362 & $104.104^{*}$ & $8.41 \mathrm{e}-07^{*}$ & $-2.669^{*}$ & $-1.677^{*}$ & $-2.435^{*}$ \\
2 & 58.934 & 11.312 & $1.79 \mathrm{E}-06$ & -2.085 & -0.299 & -1.664 \\
3 & 80.055 & 17.280 & $1.86 \mathrm{E}-06$ & -2.550 & 0.028 & -1.943 \\
\hline
\end{tabular}

* Appropriate lag length for the particular criterion.

Table-4 provides an overview of the trace values and the maximum eigen-values of the cointegration matrix. Both the trace and eigen-value tests indicate that the null hypotheses (see column 1) can be clearly accepted at the $99 \%$ significance level because the calculated values are less than their critical values. Based on these results, no cointegration vector exists in the model, and the variables do not move together in the long run. Thus, one can assume that there is no long-run relationship among the variables in concern. 
Table 4: Results of the cointegration test with JJ procedure

\begin{tabular}{llllllll}
\hline \multicolumn{1}{l}{ Trace test } & \multicolumn{5}{c}{ Maximum eigen-value test } \\
\hline$H_{0}$ & $H_{1}$ & $\begin{array}{l}\text { Trace } \\
\text { statistic }\end{array}$ & $\begin{array}{l}\text { Critical } \\
\text { value } \\
(\% 1)\end{array}$ & $H_{0}$ & $H_{1}$ & $\begin{array}{l}\text { Eigen- } \\
\text { value } \\
\text { statistic }\end{array}$ & $\begin{array}{l}\text { Critical } \\
\text { value } \\
(\% 1)\end{array}$ \\
\hline $\mathrm{r}=0$ & $\mathrm{r}>,=1$ & 36.47 & 47.85 & $\mathrm{r}=0$ & $\mathrm{r}=1$ & 16.02 & 27.58 \\
$\mathrm{r}<,=1$ & $\mathrm{r}>,=2$ & 20.45 & 29.79 & $\mathrm{r}<==1$ & $\mathrm{r}=2$ & 12.88 & 21.13 \\
$\mathrm{r}<,=2$ & $\mathrm{r}>,=3$ & 2.57 & 15.49 & $\mathrm{r}<==2$ & $\mathrm{r}=3$ & 6.83 & 14.26 \\
$\mathrm{r}<,=3$ & $\mathrm{r}>,=4$ & 0.74 & 3.84 & $\mathrm{r}<,=2$ & $\mathrm{r}=3$ & 0.74 & 3.84 \\
\hline
\end{tabular}

\section{V.III. Causality}

Causal linkages between the variables of the model estimated by Granger causality test via the VAR model considering the order of integration and optimum lag length are summarized in Figure-1. Statistically significant causalities are revealed among the variables at 10 percent significance level. Figure-1 illumines that all causal linkages are unidirectional and a significant causality from EXP to the rest of the variables exists. Additionally, GDP cause both GFCF and FDI. There is also a significant causal linkage from GFCF to FDI. Finally, results of the Granger causality test give no evidence of a causal linkage from FDI to the rest of the variables.

Figure 1: Casual linkages among the variables*

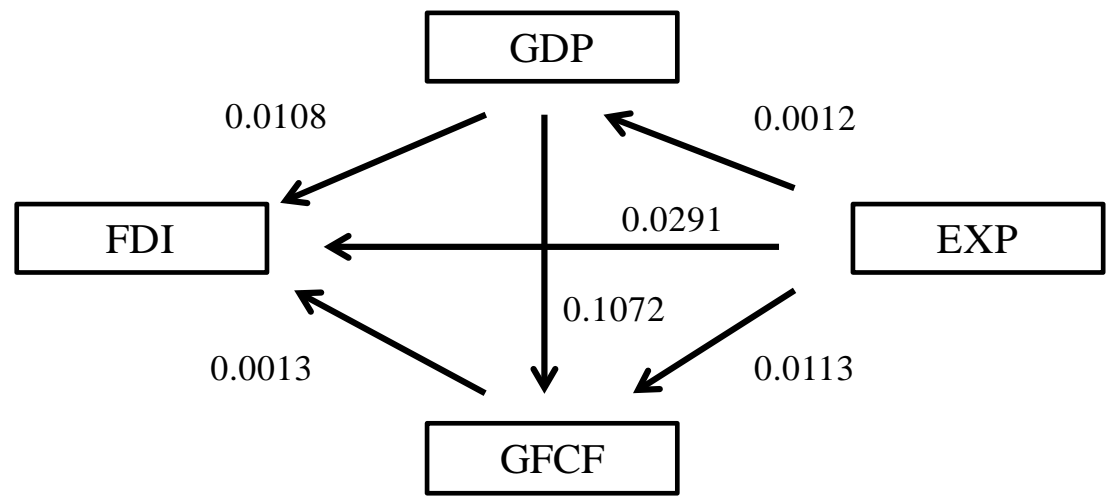

${ }^{*}$ Values represent the probability of the causal linkages. Causal linkage from GDP to GFCF is included despite to its probability value that is slightly over the $10 \%$ level.

\section{V.IV. Innovation Accounting}

The median impulse response of the FDI in the VAR model to a shock of one standard deviation in the error terms of the variables GDP, EXP and GFCF for a horizon of 10 periods are depicted in Graph-1. 


\section{Graph 1: Response of FDI to Cholesky one standard deviation innovations}

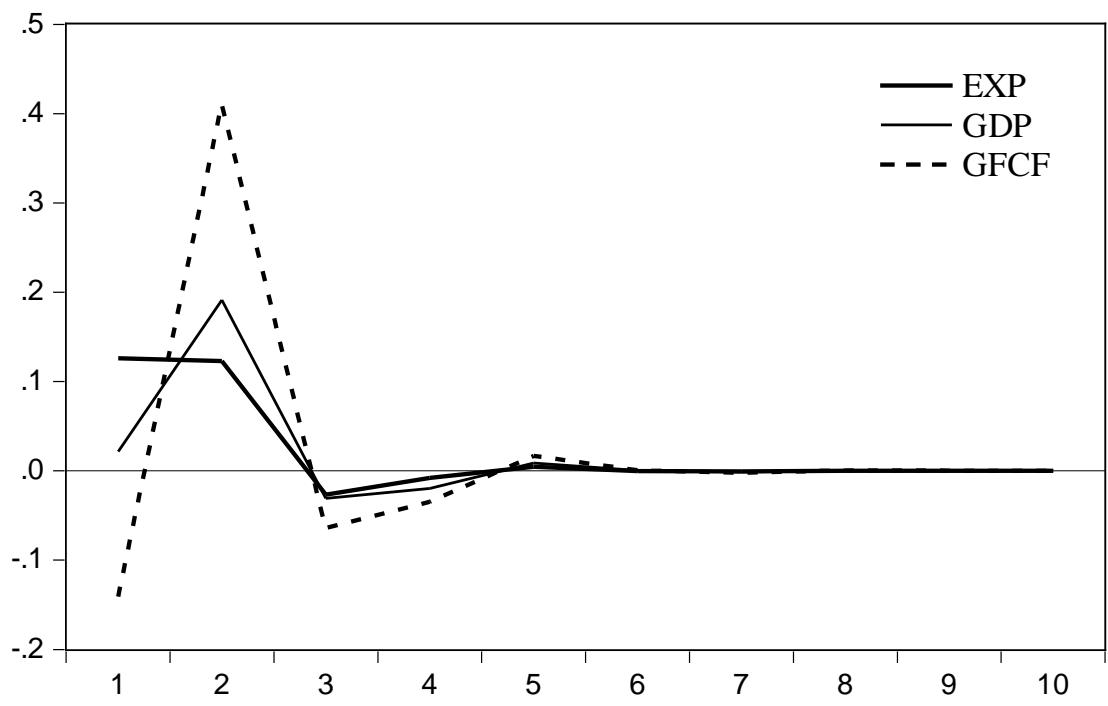

After an appreciation in the first two periods, FDI depreciates in the subsequent two periods in response to the shocks of the EXP and GDP, and then stabilizes after the fifth period. When the shock of the GFCF is considered, FDI depreciates in the first period and appreciates in the subsequent period. After depreciation in the third and fourth periods, FDI stabilizes after the sixth period.

The median impulse response of the GFCF in the VAR model to a shock of one standard deviation in the error terms of the variables GDP, EXP and FDI for a horizon of 10 periods are depicted in Graph-2. After an appreciation in the first two periods, GFCF stabilizes in response to the shock of the EXP after the third period. In the first four periods, GFCF appreciates in response to the shock of GDP except the second period and stabilizes after the fifth period. The shock of the FDI does not yield a significant response of GFCF along the horizon considered.

\section{Graph 2: Response of GFCF to Cholesky one standard deviation innovations}

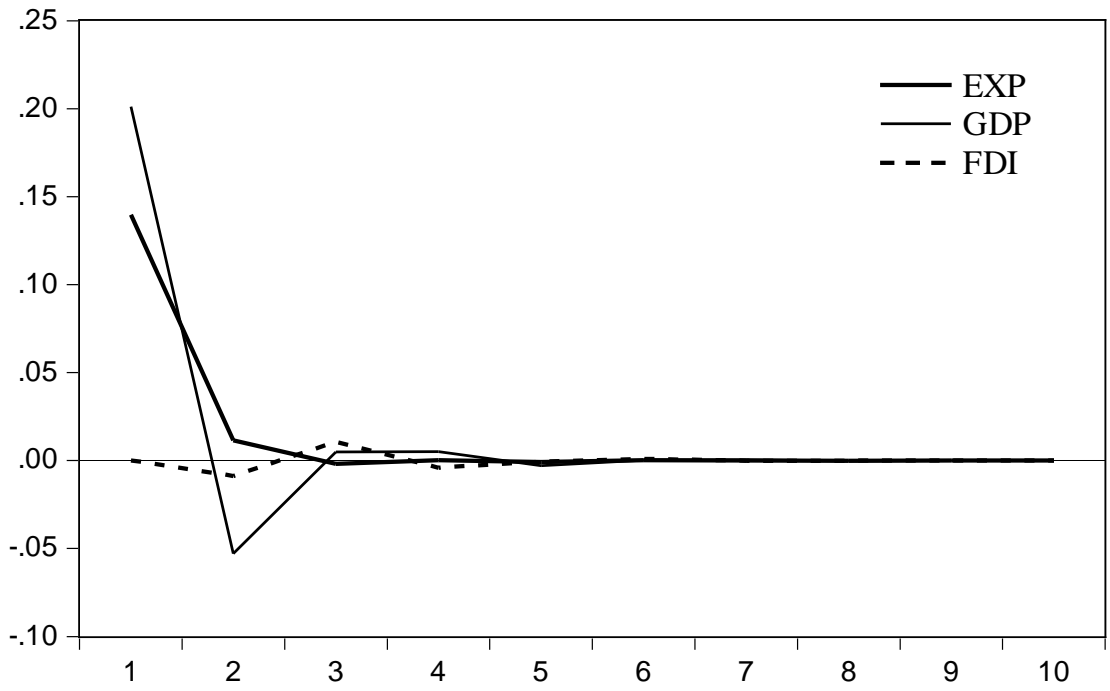


The median impulse response of the GDP in the VAR model to a shock of one standard deviation in the error terms of the variables EXP, GFCF and FDI for a horizon of 10 periods are depicted in Graph-3. After an appreciation in the first two periods, GDP stabilizes in response to the shock of the EXP after the third period. GDP does not response to the shocks of the GFCF and the FDI in the first period. However, response of the GDP to the both variable fluctuate in the subsequent five periods and finally stabilizes.

The median impulse response of the EXP in the VAR model to a shock of one standard deviation in the error terms of the variables GDP, GFCF and FDI for a horizon of 10 periods are depicted in Graph-4. In the first period, EXP does not response to the shocks of the variables. EXP appreciates in the second period in response to the shock of the GFCF and FDI, in contrast with GDP. In the subsequent four periods response of the GDP fluctuates in response of the shocks of the all variables and stabilizes after the seventh period.

\section{Graph 3: Response of GDP to Cholesky one standard deviation innovations}

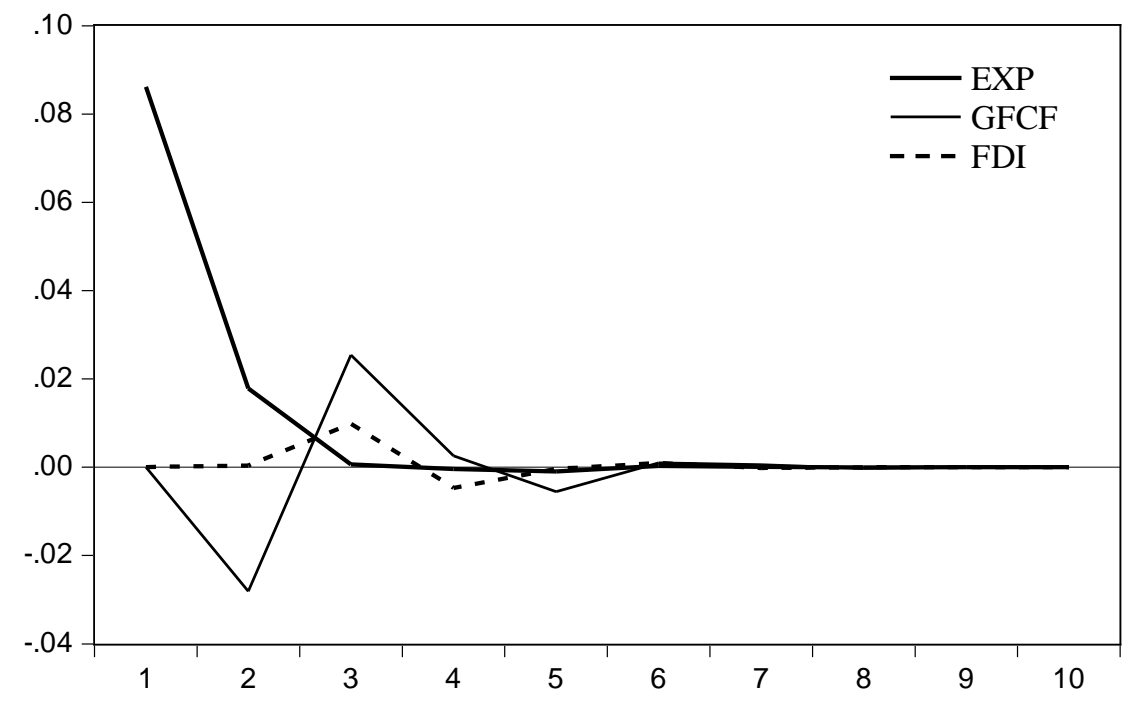




\section{Graph 4: Response of EXP to Cholesky one standard deviation innovations}

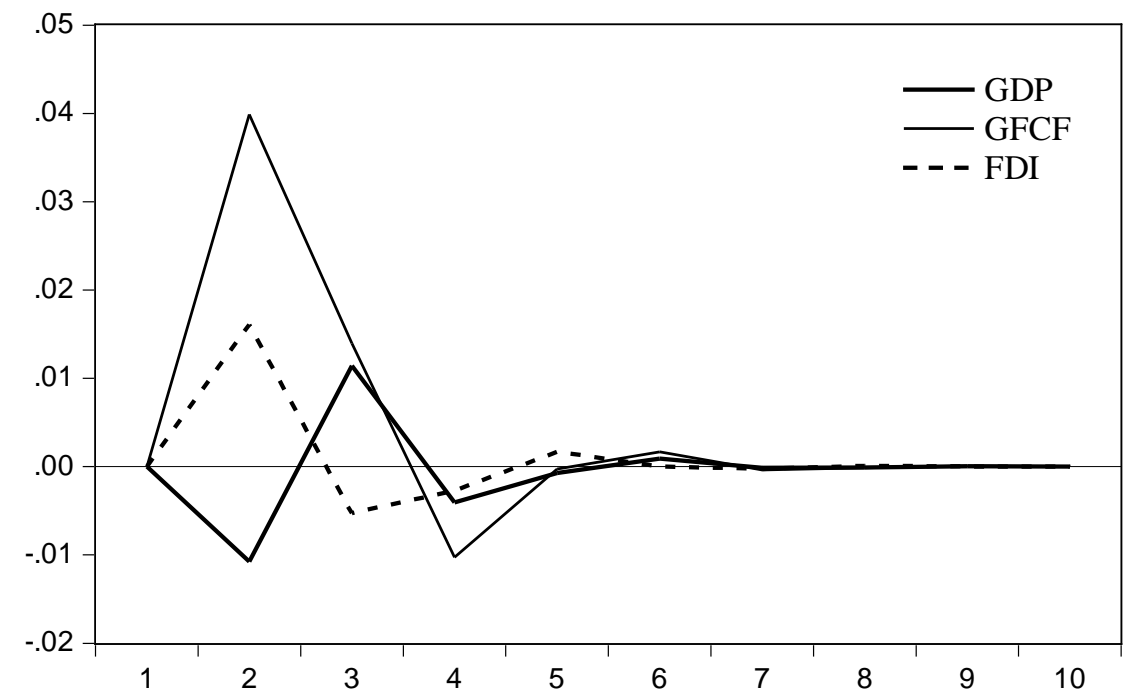

Results of the variance decomposition as a complementary technique to the impulse response are tabulated in Table-5 over a 6 year of period. Variance decomposition reveals that the forecast error variance of the EXP is completely explained by itself in the first period. At the end of the sixth period, 12.4 percent of the forecast error variance of the EXP is explained by GFCF, while the contribution of the GDP and FDI is limited to 3.6 percent in total. The forecast error variance for the GDP is explained by its innovation and EXP in the first period with a distribution of 78.8 and 21.2 percents, respectively. At the end of the sixth period, 19.8 percent of the forecast error variance of the GDP is explained by EXP, while the contribution of the GFCF and FDI is limited to 4.1 percent in total. The forecast error variance for the GFCF is explained by its innovation, GDP and EXP in the first period with a distribution of 14.2, 57.9 and 27.9 percents, respectively. At the end of the sixth period, domination of the GDP continues with a contribution of 58.1 percent to the forecast error variance of the GFCF, while the contribution of the FDI is limited to 0.3 percent. The forecast error variance for the FDI explained by its innovation is 85.6 percent in the first period, while the GFCF shock explains nearly 40 percent of the variance of the FDI in the second period. The explanatory power of the variables GDP and EXP is limited under 14.4 percent in total at the end of the sixth period, while the forecast error variance for the FDI explained by the GFCF shock stays at nearly 40 percent at the same time. 
Table-5: Variance decomposition of the variables

\begin{tabular}{ccccc}
\hline \multicolumn{5}{c}{ Forecast error variance decomposition of EXP } \\
\hline Period & EXP & GDP & GFCF & FDI \\
1 & 100.000 & 0.000 & 0.000 & 0.000 \\
2 & 86.710 & 0.782 & 10.757 & 1.749 \\
3 & 84.687 & 1.628 & 11.792 & 1.890 \\
4 & 83.973 & 1.722 & 12.380 & 1.923 \\
5 & 83.954 & 1.725 & 12.378 & 1.941 \\
6 & 83.935 & 1.730 & 12.393 & 1.940 \\
\hline \multicolumn{5}{c}{ Forecast error variance decomposition of GDP } \\
\hline Period & EXP & GDP & GFCF & FDI \\
1 & 21.204 & 78.795 & 0.000 & 0.000 \\
2 & 20.288 & 77.645 & 2.065 & 0.000 \\
3 & 19.876 & 76.192 & 3.685 & 0.245 \\
4 & 19.852 & 76.145 & 3.698 & 0.302 \\
5 & 19.834 & 76.088 & 3.774 & 0.302 \\
6 & 19.833 & 76.085 & 3.776 & 0.304 \\
\hline \multicolumn{5}{c}{ Forecast error variance decomposition of GFCF } \\
\hline Period & EXP & GDP & GFCF & FDI \\
1 & 27.933 & 57.888 & 14.178 & 0.000 \\
2 & 26.587 & 58.515 & 14.792 & 0.104 \\
3 & 26.409 & 58.147 & 15.187 & 0.254 \\
4 & 26.389 & 58.137 & 15.195 & 0.276 \\
5 & 26.378 & 58.119 & 15.224 & 0.277 \\
6 & 26.377 & 58.118 & 15.225 & 0.278 \\
\hline Period & ExXP & GDP & GFCF & FDI \\
1 & 6.294 & 0.184 & 7.876 & 85.643 \\
3 & 6.562 & 7.849 & 39.903 & 45.685 \\
4 & 6.590 & 7.901 & 40.025 & 45.482 \\
5 & 6.578 & 7.952 & 40.126 & 45.342 \\
6 & 6.577 & 7.961 & 40.150 & 45.310 \\
\hline \multicolumn{5}{c}{ Forecast error variance decomposition of FDI } \\
\hline
\end{tabular}

\section{CONCLUSION}

In this study, the impact of the technology spillovers as a potential driving force in economic growth of Turkey across the manufacturing industry was investigated between the years of 1988 and 2012. In accordance with this purpose a vector autoregression (VAR) model was adopted to explore both the long and short run relationships among the selected macroeconomic variables: FDI inflows 
to manufacturing industry, gross domestic product, gross fixed capital formation and volume of manufactured exports.

As a preliminary procedure, stationarity of the variables was checked. Augmented Dickey Fuller test revealed that all of the variables in concern are not stationary at their levels, but stationary in their first differences implying that the variables of the study are integrated at first order. Where all variables are $I(1)$, Johansen-Juselius cointegration analysis can be employed in order to investigate the existence of the long-term relationships among the variables. The findings of the cointegration analysis showed that there is no long-term relationship among the related variables. When the foreign direct investment in manufacturing industry is considered in particular, the absence of the long-term relationship can be linked with the lack of the ability of the domestic firms to use foreign direct investment as a potential source of productivity gain via technology spillovers where the level of human capital is of great importance.

It is evidently identified that short-term relationships among the variables can be established in many cases where there is no cointegration. Concerning this, Granger causality test was performed in order to assess the direction of the casual linkages if exists between the variables. Results of the causality test revealed that there is a significant unidirectional causality from the volume of manufactured exports to the rest of the variables, while there is no evidence of a causal linkage from FDI to the rest of the variables. This statement was also reinforced with innovation accounting techniques as a complementary perspective. Results of both impulse response and forecast error variance decomposition revealed that FDI positively influence growth indirectly through its significantly limited contribution on volume of the manufactured exports in Turkey for the years between 1988 and 2012.

These results are reasonable when the low level of FDI in Turkish manufacturing industry despite its remarkable potential is taken into account. Achieving a higher level of technology intensive FDI will lead Turkey to have a more sophisticated export basket that will make the country more globally competitive which yields a larger market share and consequently growth. A policy agenda which is focused on a better investment climate will help to increase the level of FDI. Additionally, the absorption capacity of the domestic manufacturing industry, as well as macroeconomic stability plays an important role for using the FDI as a driving force of the sustainable growth. Technology gap, research and development expenditures and human capital must be considered as the main indicators of absorption capacity while forming such a policy agenda. 


\section{REFERENCES}

Borenzstein, E., J. D. Gregorio, J-W. Lee (1998). "How does foreign direct investments affect economic growth?”. Journal of International Economics, 45: 115-135.

Chimobi, Omoke Philip (2010). “The Estimation of Longrun Relationship between Economic Growth, Investment and Export in Nigeria”. International Journal of Business and Management, 5 (4): 215-222.

Doytch, Nadia, and Merih Uctum (2011). "Does the Worldwide Shift of FDI from Manufacturing to Services Accelerate Economic Growth? A GMM Estimation Study”. Journal of International Money and Finance, 30 (3): 410-427

Duce, Maitena (2003). "Definitions of Foreign Direct Investment (FDI): A Methodological Note”. Paper for the CGFS Working Group, Banco de Espana. Madrid.

Durlauf, Steven N., and Lawrence E. Blume (2008). The New Palgrave Dictionary of Economics. Second Edition.

Enders, Walter (1995). Applied Econometric Time Series. New York: John Wiley \& Sons, Inc.

Hansen, Henrik, and John Rand (2005). “On the Causal Links between FDI and Growth in Developing Countries”, UNU-WIDER. United Nations University (UNU). Research Paper No. 2005/31.

IMF (2009). Balance of Payments and International Investment Position Manual. Sixth Edition (BPM6). Washington. D.C.: IMF.

Kar, Muhsin ve Fatma Tatlısöz (2008). “Türkiye'de Doğrudan Yabanc1 Sermaye Hareketlerini Belirleyen Faktörlerin Ekonometrik Analizi”, KMU İ̈BF Dergisi, 10 (14): 436-458.

Lipsey, Robert E., and Fredrik Sjöholm (2005). “The Impact of Inward FDI on Host Countries: Why Such Different Answers?” in Theodore H. Moran, Edward M. Graham, and Magnus Blomström (eds.). Does Foreign Direct Investment Promote Development?. Washington: Institute for International Economics Center for Global Development.

OECD (Organization for Economic Cooperation and Development, 2008). OECD Benchmark Definition of Foreign Direct Investment. 4th Edition. Paris. Available at www.oecd.org (accessed on June 11, 2009).

Saggi, Kamal (2002). “Trade, Foreign Direct Investment, and International Technology Transfer: A Survey”, The World Bank Research Observer, 17 (2): 191-235.

Sonmez, Alper, and M. Teoman Pamukcu (2011). "Foreign Direct Investment and Technology Spillovers in the Turkish Manufacturing Industry”. STPS Working Papers 11/03. STPSScience and Technology Policy Studies Center. Middle East Technical University.

Turan Koyuncu, Fatma (2010). “Türkiye'de Seçilmiş Makroekonomik Değişkenlerin Doğrudan Yabancı Sermaye Yatırımları Üzerindeki Etkisinin Yapısal VAR Analizi: 1990-2009 Dönemi”, Ekonomi Bilimleri Dergisi, 2 (1): 55-62. 
Wang, Miao (2009). "Manufacturing FDI and Economic Growth: Evidence from Asian Economies", Applied Economics, 41 (8): 991-1002. 